\title{
Sustainable steel and composite constructions for multifunctional commercial buildings
}

\author{
R. Stroetmann ${ }^{\text {a** }}$ L. Hüttig ${ }^{\mathrm{a}}$

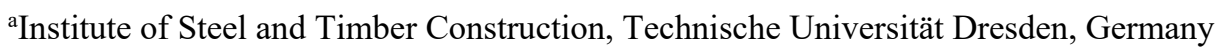 \\ *corresponding author, e-mail address: richard.stroetmann@tu-dresden.de
}

\begin{abstract}
Rising cost pressures and the prospect of quick returns have led to an increase in mono functional buildings since the 1970s. These prevent the adaptation to changing user requirements with little monetary outlay. Lack of marketability, increasing vacancy and early demolition are often the consequences. Main objective of the AIF/FOSTA research project $\mathrm{P} 1118$ [1] is to develop planning recommendations for multifunctional usable buildings. Adaptability to changing needs will increase marketability and value stability as well as extend the lifetime of the buildings. This not only increases the economy but also the resource efficiency.

First of all, the paper explains the ecological and economic requirements for modern buildings, which are based on current certification systems. In this context, the expected lifetime of primary and secondary building components are also dealt with. Subsequently, relevant types of use as well as requirements for essential building parameters are presented. In a comparison, the ecological expenses and costs are assessed for four selected composite structures. For the multifunctional building structures an extension of lifetime is considered and the environmental and monetary impacts are assessed. Furthermore, the influence of the structure on the building foundations is analysed. The investigations present the effects of the building masses on the foundations for two different soil conditions. Finally, the investigations show that variable usable buildings with a longer lifetime lead to a better sustainability.
\end{abstract}

Keywords: multifunctional buildings; composite ceiling systems; sustainability; life cycle assessment.

\section{Introduction}

The real estate industry is facing new challenges. The consequences of the demographic change of our society, the structural development of cities and the need to reduce the global warming require more suitable solutions. Key objectives for the life cycle of buildings are the reduction of energy consumption, emissions and waste. This can be achieved by optimized building constructions and the extension of lifetime. Buildings must be designed in such a way that they not only meet current user requirements, but also future ones. A survey by the European Commission found that office buildings undergo a change in use every 11.6 years [3-4]. Experience of recent decades shows that the construction of low-cost mono-functional building structures and neighbourhoods, as they are implemented in many places of Europe since the 1970s, often lead to premature vacancy up to demolition because sufficient adaptability of the primary structure is not given. Future buildings should be designed in such a way, that they allow a change in use with little monetary and time expenditure. Thus, it is necessary to create buildings with a primary structure that meets the requirements of different types of use relevant for the location. If change of use happens, adjustments should be limited to the secondary structures.

In the AIF / FOSTA research project P881, the development of design recommendations for sustainable office buildings in steel and composite construction was carried out by the interdisciplinary cooperation of architects, structural engineers, ergonomists and 
economists. In this context, the analysis of rating systems for sustainability, the development of methods for evaluating building constructions, structural optimizations for flexible office layouts and the compilation of databases for the assessment of the economy and ecology of buildings were carried out.

Based on the results of P881 the AIF/FOSTA project P1118 followed to develop multifunctional office and commercial buildings. In addition to the focus on the functionality of the buildings, a more comprehensive approach was taken to design and evaluate the building structures, including the facades and foundations. On the basis of test designs for reference buildings with different functionality, the respective constructional efforts were identified. To evaluate the benefits of increased functionality for the real estate industry, stochastic modelled full financial plans were used. The investigations show that the additional expenses for creation of functionality in building construction are moderate. The earnings situation is improved by a higher rent and a lower probability of rent losses. In addition, the residual value of the real estate increases at the end of an evaluation period. The longer service life and fewer efforts due to conversions increase the resource efficiency of the building structures.

\section{Assessment of Sustainability}

\subsection{Certification of buildings}

The assessment of sustainability takes place by various certification systems. The British system BREEAM and the US system LEED are the international leading systems. In Germany, the systems DGNB (Deutsches Gütesiegel für Nachhaltiges Bauen) for public buildings and BNB (Bewertungssystem Nachhaltiges Bauen für Bundesgebäude) for federal buildings have been developed. Compared to BREEAM and LEED an equal rating of the three aspects ecology, economy, socio-cultural and functional quality is taken by DGNB and BNB. Thus, the German systems are also referred to as systems of the second generation. In addition, the technical and the process quality are taken into account as relevant properties in all areas. Meanwhile, in addition to office and administration buildings other types of buildings, such as hotels, commercial buildings, education centres, industrial buildings and parking garages can be assessed.

\subsection{Ecological Sustainability}

The evaluation of the ecological quality follows by the Life Cycle Assessment (LCA) of buildings and its components. This includes the phases of product manufacturing, construction, the use stage and disposal. In addition, credits and debits beyond the life cycle for reuse, recovery and recycling will be considered. The environmental indicators (e. g. global warming potential and primary energy demand) for building materials and products are collected in databases and environmental product declarations (EPD). An overview is given in [4].

The evaluation systems DGNB and BNB assume a lifetime of 50 years for the assessment of the ecological impact of buildings. If components have a shorter service life, they have to be replaced once or several times during the life cycle of a building. In this case the environmental impacts have to be multiplied. Various studies have been carried out to assess the service life of components (see [5-7]). The results are based on statistical evaluations for existing buildings. The lifetime of building components is given as a range of minimum and maximum duration. Partly, the sources show big differences in their rating. Furthermore, there are still insufficient empirical values for many relevant components and construction products. Hence, RITTER $[8,9]$ calculated the lifetimes based on data of existing constructions as well as probabilistic methods considering the material influences. This made it possible to rate the life span of new components without existing data.

Fig. 1 shows the determined lifetime of selected components. In particular, the elements of the primary structure (foundations, columns, ceilings) have a long lifetime. The average is rated with 83 to 100 years. Secondary elements, such as facades, windows, suspended ceilings and fire protection, have much lower average service life of 22 to 58 years. The lifetime of buildings is not limited by the durability of the supporting structures. It is the out-dated building equipment, the need of modernisation and repair, which do not allow a contemporary and adequate use. Consequently, designing an appropriated building structure, which considers the relevant types of use, can elongate the lifetime of a building. Thus, the refurbishment can be limited to secondary components. 


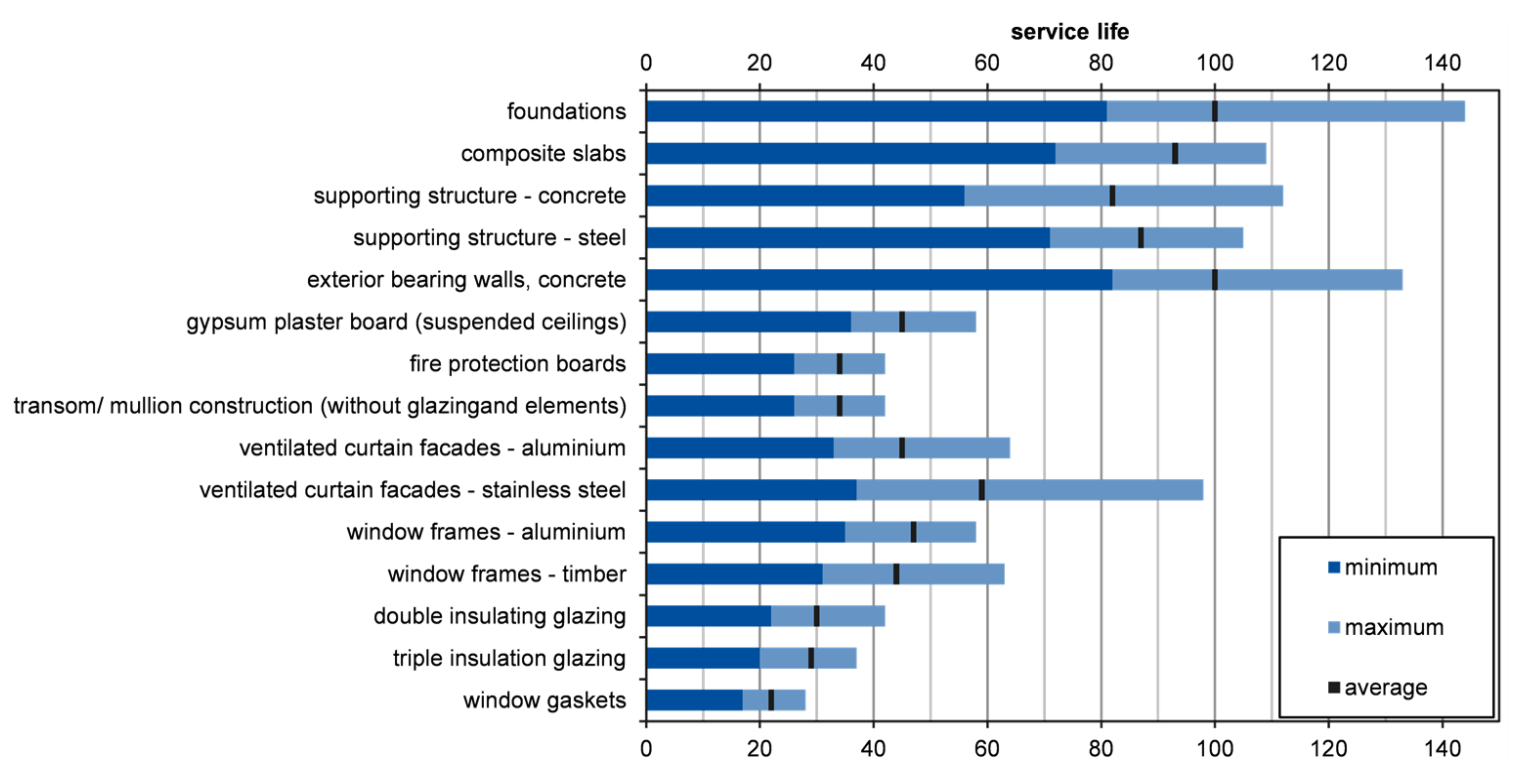

Fig. 1. Technical lifetime of building components according to [9]

\subsection{Economical Assessment}

The economic assessment takes into account the building-related life cycle costs (LCC) as well as the efficiency, adaptability and the lasting value. Table 1 provides an overview of the criteria given by BNB and DGNB for office and administration buildings and their shares in the overall assessment. The construction costs of the buildings become less important. The influence of the follow-up costs as well as the efficiency, flexibility and lasting value increase. Scopes of the evaluation are criteria like

- clear storey height and building width,

- vertical access of the building,

- floor plan design (size of units, space for mechanical services, emergency exits etc.),

- construction of inner- and partition walls,

- level of imposed loads and their reserves,

- technical equipment for air condition, building automation, installation centres,

- possibility of space use in small units,

- possibility to use renewable energy.

Depending on the type of building different requirements are placed on the mentioned criteria. Space efficiency and adaptability can be achieved by appropriate floor plan design, building width, clear storey heights, building access, including relevant usage scenarios and appropriate revisable technical installations. Flexible buildings are characterized by floors without or at least optimally positioned inner columns involving various usage scenarios. Partition walls should be connectable in each axis of the façade grid, not extend into the floor and ceiling structure, dust-free mountable and reusable.

Under the conditions for a space-efficient and flexible building and the assumption that the costs for operating and maintenance are largely independent of the bearing structures, the optimization and comparison of building structures can be made on the manufacturing costs. Prices for building materials, performance values for productivity and salaries depend on regional, temporal and economic fluctuations. In the research project P881, a compilation of manufacturing costs and work processes for bearing structures of buildings was made. It was based on researches and experience of various companies from the German-speaking countries. The results of the parametric studies were rated as a percentage of the respective peak value $(100 \%)$. This corresponds to a relative comparison, disposing the effect of these variations on the results as far as possible. This applies as long as the relations of the expenses remain in the system.

Table 1.Criteria of the economic quality of office buildings (cf. BNB, DGNB).

\begin{tabular}{|c|c|c|}
\hline content & BNB & DGNB \\
\hline $\begin{array}{l}\text { building-related } \\
\text { life cycle costs }\end{array}$ & $11.25 \%$ & $9.64 \%$ \\
\hline $\begin{array}{l}\text { profitability, } \\
\text { lasting value, } \\
\text { performance }\end{array}$ & $\begin{array}{c}\text { space } \\
\text { efficiency } \\
3.75 \% \\
\text { adaptability } \\
7.5 \%\end{array}$ & $\begin{array}{c}\text { flexibility and } \\
\text { conversion } \\
\text { feasibility } \\
9.64 \% \\
\text { marketability } \\
3.21 \%\end{array}$ \\
\hline
\end{tabular}




\section{Design of multifunctional buildings}

The boundary conditions and design parameters for the bearing structures arise from the building requirements and the specified grids of facades and columns. This includes the spans of slabs and beams, floor heights, imposed and additional dead loads, fire protection, the design of components and installation spaces. A selection of appropriate construction systems, components and design principles, which fulfil the requirement under consideration of sustainability criteria in an optimum, has to be taken.

A systematic procedure for the design of the building structures is to deduce the essential parameters of the relevant usage scenarios. The choice of scenarios should consider the building location (e. g. city center or suburb) and the current and future needs. Furthermore, it is preferable to distinguish between floors within the building because certain uses will preferably be positioned in certain floors. Typical allocations are underground parking and storage areas in the basement, retail on the ground floor, office, residential and hotel uses on the upper floors. Specific requirements resulting from the type of use, e. g., the width of the building, storey height, imposed loads, access to the building and technical equipment. Vice versa, the suitability of the building parameters to specific usage can be carried out. According to the previous descriptions, in P1118 the essential characteristics of building parameters for the design of bearing structures were examined. Some individual parameters are explained in the following.

In Europe the assumptions for dead and imposed loads are carried out by EN 1991-1-1 and the country-specific national annexes. Fig. 2 shows a comparison of the imposed loads, which are applicable with a surcharge for partition walls for different types of usage taking into account the German national annex. Floors for office, residential and hotel usage can be designed for a relatively low imposed load $\left(\leq 3.0 \mathrm{kN} / \mathrm{m}^{2}\right)$. For retail, convention centres and gastronomy areas, imposed loads up to $5.0 \mathrm{kN} / \mathrm{m}^{2}$ have to be considered. Storage and archive space require even higher loads. The amount of additional dead load depends on the ceiling construction. The use of suspended ceilings and double floors creates a high degree of flexibility for technical installations and subsequent use changes. If the floors are rented to different users, the combination of both systems may be relevant.

Fig. 3 shows appropriate and possible storey heights for different types of use. The various usage requirements lead to different storey heights. Parking levels can be built with a clear height of $2 \mathrm{~m}$. For residential and office uses clear heights starting from $2.50 \mathrm{~m}$ are suitable. For retail larger clear storey heights are necessary depending on the sales areas.

\section{Assessment of bearing structures}

\subsection{Steel and composite structures}

With steel and composite structures, various user requirements can be fulfilled. For instance, with the use of long-span ceiling systems interior columns can be avoided. This increases the flexibility in the floor plan design. The ceilings, which generally include downstand composite beams (DSB), provide the necessary space for

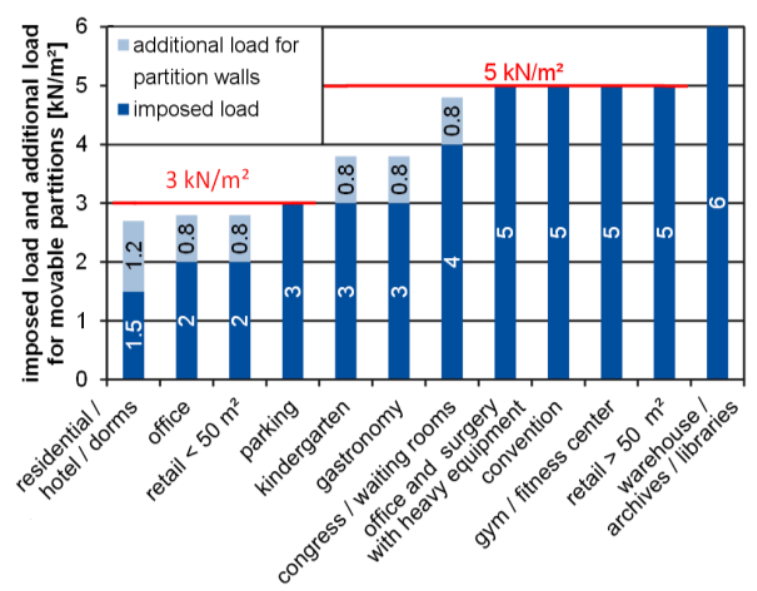

Fig. 2. Imposed loads and additional loads for partition walls for various types of use

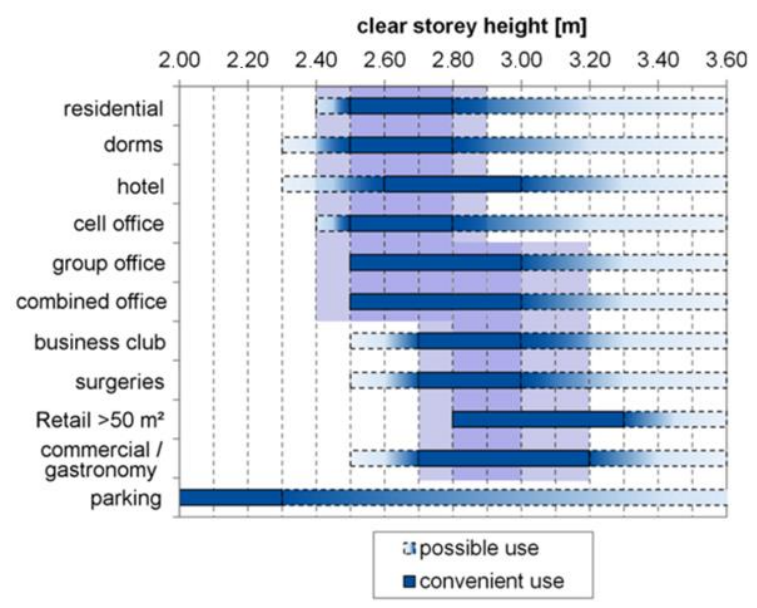

Fig. 3. Appropriate and possible clear storey heights for different types of use 
technical building equipment. Slim floor systems, using integrated floor beams (IFB) or slim floor beams (SFB), have a significantly lower construction height. They generally require inner columns. In the case of slim floor systems or slabs with composite beams and insufficient structural height, the technical equipment has to be installed below the structure level and/or in the above-lying double or cavity floors.

Based on the results of the project P881 [3], buildings with different degrees of variability were designed and optimized according to ecological and economic criteria in project P1118 [1]. The definition of "variability" refers to the possibility of the variety of uses of the buildings, which results in corresponding requirements for the building structures. For example, the higher the clear storey heights and ceiling load capacities, the lower are the resulting restrictions on use (see section 3).

The investigations in project P1118 include i.a. the structures of the buildings, structural fire protection, building foundations and facade systems. The influence of the increasing variability of a building on the environmental and costs is shown. The additional expenses in the phase of construction and maintenance are compared with the savings due to changes in use, stability of value and marketability as well as the extension of the life cycle. Subsequently, individual studies from the project are presented.

Fig. 4 shows the cross sections of reference buildings with low and high variability. The low variable building has inner columns and a clear storey height of $3.50 \mathrm{~m}$ in the ground floor and $2.75 \mathrm{~m}$ in all upper floors. The imposed load on the ceilings of the upper floors, including additional load from partition walls, is 3.0 $\mathrm{kN} / \mathrm{m}^{2}$. This leads to a limitation of the frequent forms of use office, residential, hotel and similar. Integrated floor beams (IFB) with composite slabs and high trapezoidal sheets as well as prestressed hollow core slabs are considered as ceiling systems (Fig. 5). The system with composite slabs is designed with a beam and column spacing of $5.40 \mathrm{~m}$. The system with the long prestressed concrete slabs has a beam and column spacing of $8.10 \mathrm{~m}$. The integrated floor beams and composite slabs do not need additional fire protection, since in case of fire, the failure of the lower flanges and profile sheets will be compensated by appropriate reinforcement in the concrete.

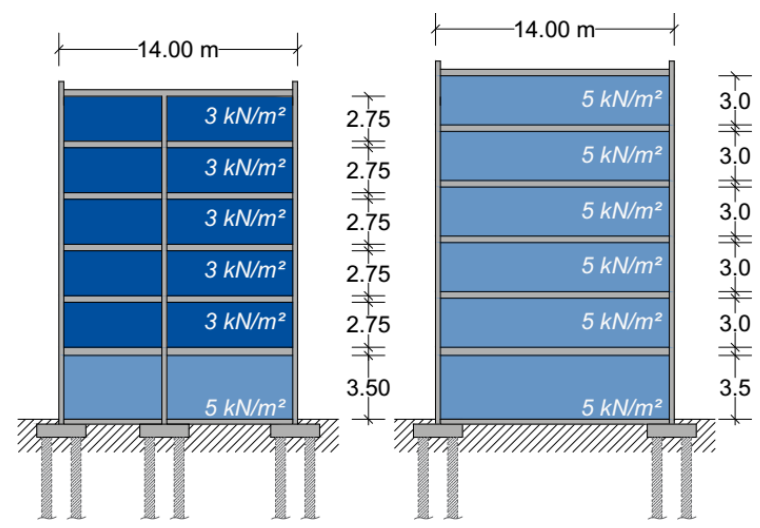

Fig. 4. Cross sections of the reference buildings with low and high variability

The technical installation is arranged in the corridor area. This results in a reduction of the clear storey height in this area to $2.50 \mathrm{~m}$.

The building with high variability is planned without inner columns. The upper floors have a clear storey height of $3.0 \mathrm{~m}$ and are designed for imposed loads of $5.0 \mathrm{kN} / \mathrm{m}^{2}$. With these parameters all types of use, except storage and archive use, are possible. In addition, a raised floor is considered in order to increase the variability of the storeys regarding the technical installation. Necessary adaptations can be made as far as possible within the storeys, in which the changes take place. Due to the span of the ceilings, composite slabs with downstand beams (DSB) are considered. As Fig. 5 shows, two structural systems with a column distance of $5.40 \mathrm{~m}$ are examined. In the first system, the beam and column spacings are the same. A composite slab with $155 \mathrm{~mm}$ thickness is considered. The second system has a beam spacing of $2.70 \mathrm{~m}$. Thereby the required construction height is reduced. In static terms, a composite slab with $100 \mathrm{~mm}$ height is sufficient. Supports during assembly can be omitted. To reach a fire resistance F90 for the steel beams, a $25 \mathrm{~mm}$ thick U-shaped rock wool panelling is used.

\subsection{Ecological and economic assessment}

Fig. 6 shows the comparison of the building material demand for the ceiling systems and columns in relation to the generated gross floor area (GFA). In the low variable building the structural steel demand decreases with the larger beam spacing. The masses of the ceilings with high profile sheets and those with prestressed 
hollow core slabs differ only slightly. For the ceilings with downstand beams the reduction of the beam spacing and the arrangement of edge
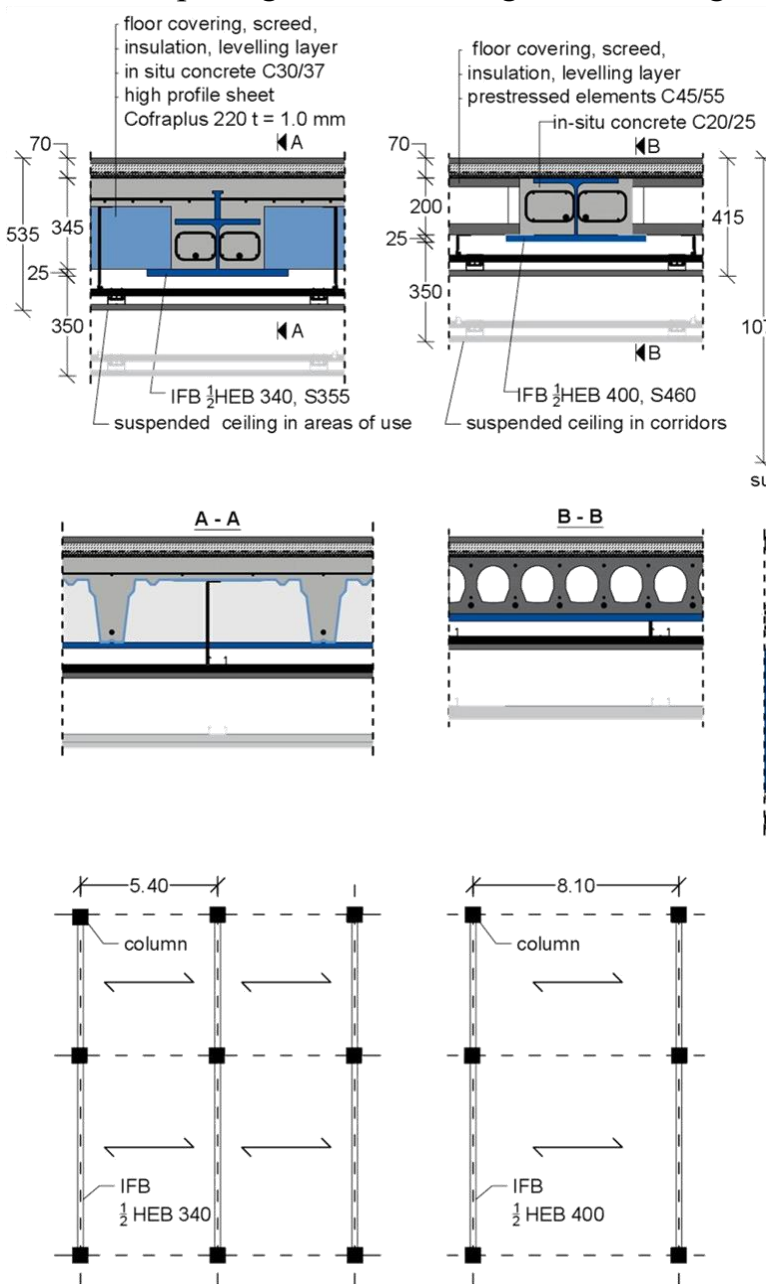

Fig. 5. Cross and longitudinal sections; view of the ceiling systems with beam and column spacings

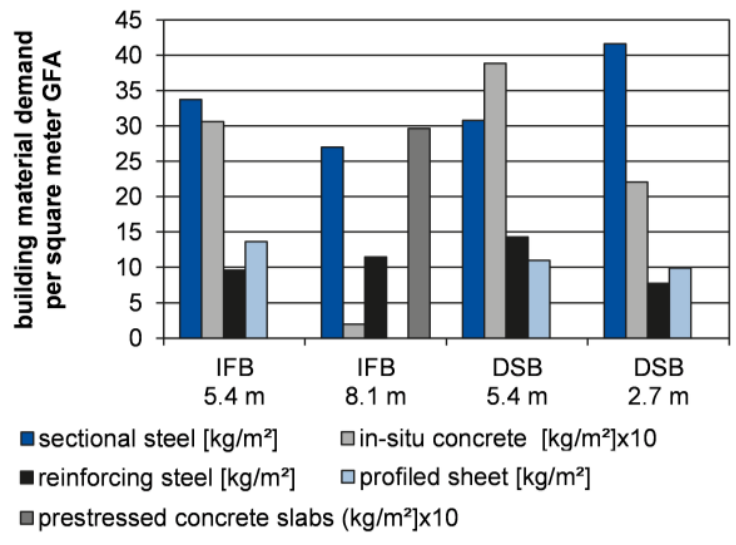

Fig. 6. Building material demand of the ceiling systems and columns per $\mathrm{m}^{2}$ gross floor area (GFA)

Fig. 7 shows a comparison of the primary energy demand and the relative manufacturing costs of the supporting structures. The values are given with reference to the lifetime of the
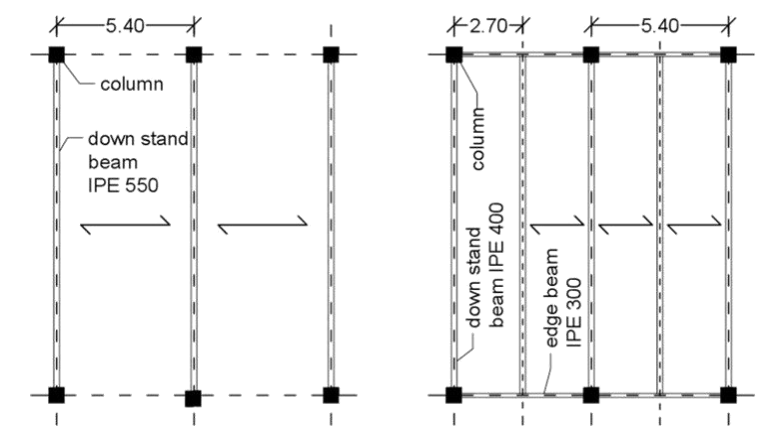

beams leads to a higher sectional steel demand. On the other hand, the masses of the reinforcement and in-situ concrete are reduced.
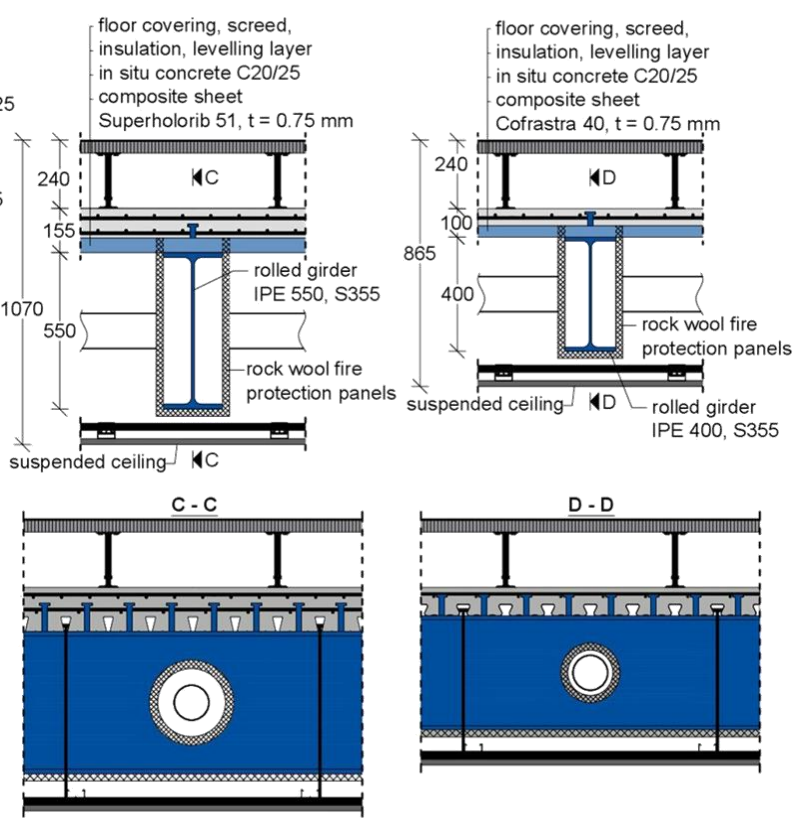

buildings. Obviously, the integrated floor beams (IFB) with prestressed concrete slabs lead to the lowest costs. The ceilings with downstand beams (DSB) and a spacing of $2.70 \mathrm{~m}$ have the highest costs due to the increased steel demand and the fire protection. If a longer lifetime is taken into account due to the higher variability, the annual costs will decrease. This includes that rock wool fire protection panels will have to be replaced after 50 years (see EPD [10]). After 10 years of longer service life, the related building costs of the low and high variable buildings are approximately the same. If the lifetime of the high variable building can be increased up to 75 years, the related manufacturing costs will be up to $25 \%$ lower than the values of the low variable building.

Regarding the primary energy demand, slimfloor-systems (IFB) with a beam spacing of $8.10 \mathrm{~m}$ have the highest values. This results 

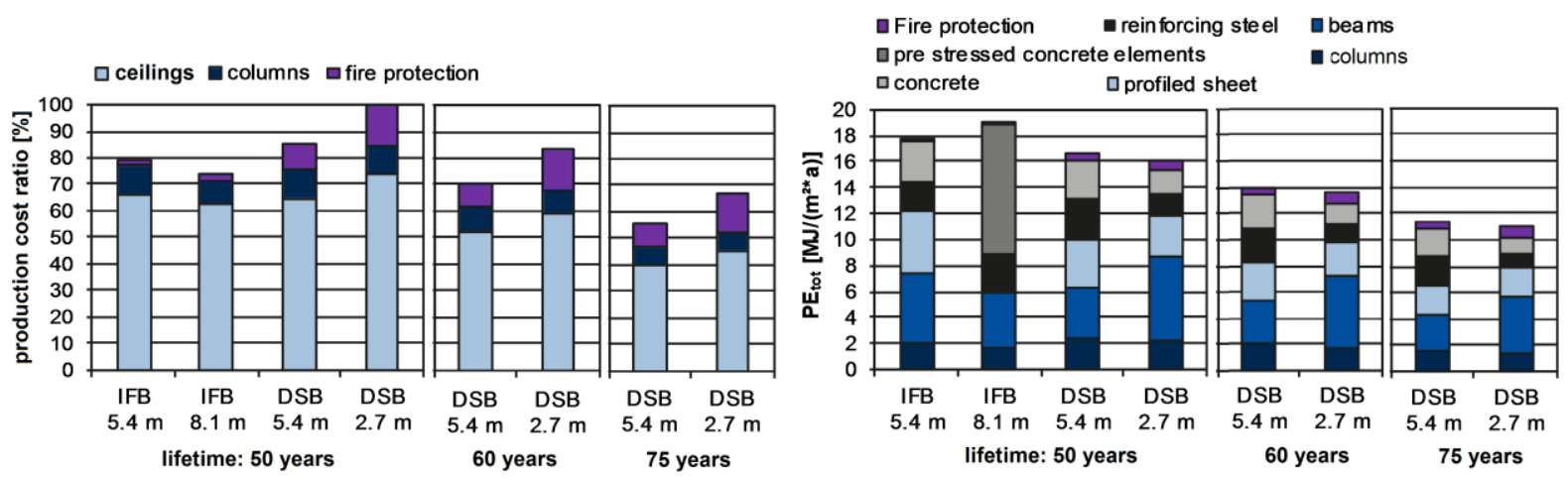

Fig. 7. Lifetime related costs and primary energy demand for ceilings, columns and fire protection
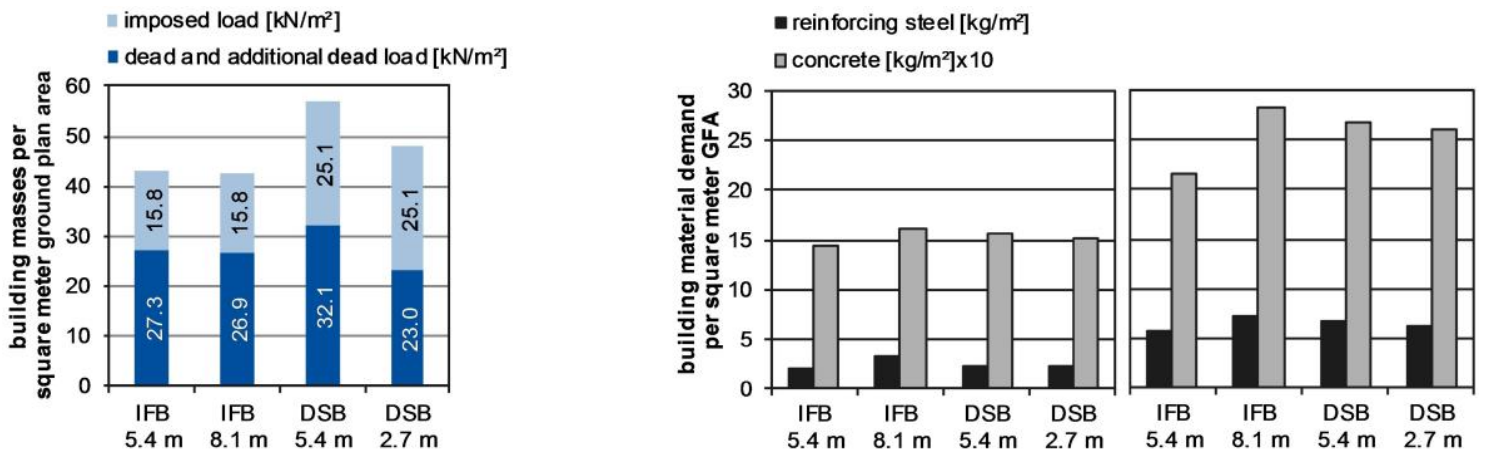

Fig. 8. Load per $\mathrm{m}^{2}$ ground plan area; building material demand for flat and pile foundations

mainly from the influence of the prestressed concrete hollow slabs. Because of their material efficiency, the ceilings with downstand beams lead to lower environmental impacts than the slim-floor-systems. Despite of the higher consumption of sectional steel, the system with $2.70 \mathrm{~m}$ beam spacing produces the lowest primary energy demand due to the savings in concrete and reinforcement. The influence of structural fire protection with rock wool panels is low for all bearing structures. By extending the lifetime to 75 years, the environmental impact of the high variable building is reduced down to two-thirds of the low variable one.

\subsection{Influence of the building foundation}

The foundation of a building will be designed depending on the predominant soil and groundwater conditions at the respective location. Depending on the loads and the loadbearing capacity of the soil, flat or deep foundations are carried out. Partially, deep foundations can be avoided by soil improvement.

In order to assess the influence of the bearing structure and the column loads under different soil conditions, two situations were investigated. In the first case, a stable mixed-grained soil was assumed. Thus, flat single foundations were possible. The foundations were designed according to DIN EN 1997-1 and the German national annex. In the second case, a mediumplastic tone was assumed. Consequently, single foundations with partial displacement bored piles $(\mathrm{D}=60 \mathrm{~cm})$ were considered. The number and length of the piles were calculated for the acting loads.

Fig. 8 shows the permanent and imposed loads per square meter ground plan area as well as the building material demand for the flat and pile foundations in relation to the gross floor area (GFA) of the buildings. The comparison of the flat foundations show that the differences in the building material consumption are smaller than the relation of the acting loads. The numbers of foundations differ in the variants due to the different column spacings in longitudinal direction of the buildings $(5.40 \mathrm{~m}$ and $8.10 \mathrm{~m})$ and the lack of inner columns under the ceilings with downstand beams. The pile foundations show greater differences in the building material consumption. The building with IFB and prestressed hollow core slabs shows the lowest load per $\mathrm{m}^{2}$ foundation area, but requires the largest building material demand. Indeed, the number of foundations is reduced due to the column distance of $8.10 \mathrm{~m}$, but the individual loads are higher. As the volume of the 
foundations increases disproportionately with the load, significantly larger concrete masses are required.

\section{Summary and outlook}

The lifetime of multi-storey buildings is highly dependent on the adaptability to changing user requirements, especially in cities. If bearing structures are designed in such a way, that the relevant forms of use are possible, modification measures are limited to the interior constructions and, if necessary, the building facades. As the building stock shows, appropriately executed bearing structures can be used for more than 100 years. Steel and composite constructions enable a floor plan design without inner columns and have a higher adaptability. The lighter construction compared to conventional reinforced concrete structures reduces building materials, foundation loads and its costs. Minor modifications save resources and minimize usage restrictions. Investors and clients benefit from higher value stability and marketability of the buildings. Rent losses will be reduced and a premature dismantling avoided.

In order to achieve the adaptability of buildings, the relevant usage scenarios have to be respected in the planning. The consideration of sufficiently high imposed loads and clear storey heights, the possibility to exchange and retrofit the technical installation under suspended ceilings, double or cavity floors increase the flexibility. In addition, a suitable access to the building units, the possibility of small-scale usage and the necessary precautions for adequate fire protection must be observed. The additional expenses for the bearing constructions have a lower influence on the total costs and are a good investment in the sustainability of the buildings.

This paper presents an overview of planning flexible and sustainable buildings in steel and composite construction. Individual aspects, such as the design and assessment of ceiling systems and their effects on foundations under different soil conditions are treated. As part of the project P1118, a research team consisting of architects, civil engineers, project developers and construction companies investigated several aspects of architectural and constructional design. Numerous studies were carried out, including the floor plan design, supporting structures, facades, technical installations, economic efficiency and sustainability. Reference buildings were examined and planning recommendations for designing adaptable buildings were developed. The research report [1] and the project manual for P1118 will be available soon.

\section{References}

[1] Stroetmann R, Eisele J, Otto J, et al., Einflüsse der Stahl- und Verbundbauweise auf die Lebenszykluskosten und Vermarktungsfähigkeit multifunktionaler Büro- und Geschäftshäuser. In progress. Report: P1118.

[2] Directorate-General for Research and Innovation (European Commission), Evaluation of client demand, sustainability and future regulations on the next generation of building design in steel. European Commission; 2007.

[3] Mensinger M, Stroetmann R, Eisele J, et al., Nachhaltige Büro- und Verwaltungsgebäude in Stahl- und Stahlverbundbauweise. Verlag und Vertriebsgesellschaft mbH; 2016. Report: P881.

[4] Kuhlmann U, (editor), Stahlbau-Kalender 2016. 18. Jahrgang. Wilhelm Ernst \& Sohn; 2016.

[5] Bahr C, Lennerts K., Lebens- und Nutzungsdauer von Bauteilen. Bundesinstitut für Bau-, Stadt- und Raumforschung (BBSR) und Bundesamt für Bauwesen und Raumordnung (BBR); 2010. Report: 10.08.17.7-08.20.

[6] Lebensdauer von Bauteilen und Bauteilschichten. Bundesamt für Bauwesen und Raumordnung (BBR); 2006.

[7] Asam C, Dorn S, Hänel M, et al., Nutzungsdauerangaben von ausgewählten Bauteilen und Bauteilschichten des Hochbaus für den Leitfaden "Nachhaltiges Bauen". Institut für Erhaltung und Modernisierung von Bauwerken e.V. an der TU Berlin; 2007.

[8] Ritter F. Dissertation zur Lebensdauer von Bauteilen und Bauelementen - Modellierung und praxisnahe Prognose. Fachbereich Bauingenieurwesen und Geodäsie der Technischen Universität Darmstadt; 2011.

[9] Ritter F, Kalusche W, Kalusche J., BKI Baukosten 2016 Neubau - Statistische Kostenkennwerte für Bauelemente. Baukosteninformationszentrum Deutscher Architektenkammern GmbH; 2016.

[10] Deutsche ROCKWOOL Mineralwoll GmbH \& Co. OHG., Steinwolle-Dämmstoffe im hohen Rohdichtebereich; 2012. 